\title{
Sustaining the National Health Insurance Scheme in Ghana: Perceptions and Experiences of Health Care Providers and Subscribers
}

\author{
Amangbey Emmanuel (Corresponding author) \\ Claims Processing Centre-CPC Tamale \\ National Health Insurance Authority, Ghana \\ E-mail: amagrnewton@gmail.com
}

Gandiibu A. Julius

Claims Processing Centre-CPC Tamale

National Health Insurance Authority, Ghana

E-mail: gandiibuj@gmail.com

Gbaran Gbolo

Claims Processing Centre-CPC Tamale

National Health Insurance Authority, Ghana

E-mail: gbologbaran1975@gmail.com

Received: August 2, 2017 Accepted: August 16, 2017 Published: December 28, 2017

doi:10.5296/ijssr.v6i1.11633 URL: http://dx.doi.org/10.5296/ijssr.v6i1.11633

\begin{abstract}
The establishment of the National Health Insurance Scheme was as a consequence of government effort at adopting a sustainable health care financing system with the aim of achieving universal health coverage. This study therefore explored the perceptions and experiences of health care providers and subscribers regarding the sustenance of the NHIS in Ghana. The study employed a mixed method design using survey questionnaires and in-depth
\end{abstract}


face-to-face interviews. The study revealed that NHIS had contributed to the revenue base of service providers and increased healthcare utilisation at provider centres. The inability of health care providers to provide essential medicines and perceived poor quality of health care were identified as challenges to subscribers. The study concludes that the NHIS has the potential of ensuring universal health coverage provided stakeholders make deliberate efforts at addressing the obvious sustainable threats identified.

Keywords: health care financing, National Health Insurance Scheme, sustainability

\section{Introduction}

Universal health coverage (UHC) has become a major goal for health reform in many countries. Financing is a key driver of UHC and many countries including low and middle income countries are seeking for better options to modify their health financing systems to support the realisation of UHC (Addae-Korankye, 2013). Health care financing strategies have gained a lot of attention in international health policy debate and research (McIntyre, 2007). Ghana is among the first countries in sub-Saharan African to introduce national health insurance scheme (NHIS) in 2003 aimed at providing financial access to enhance quality basic healthcare (Owusu-Sekyere \& Chiaraah, 2014). Post-independence in Ghana witnessed the establishment of a National Health Service (NHS) that was mainly financed from state revenue (Owusu-Sekyere and Bagah, 2014). This system of health delivery ensured that the citizenry received health services without any costs and as such insulated the poor and marginalised from financial distress (Frimpong, 2013). The sustainability of the NHS was threatened due to the economic crisis in the 1970s and early 1980s which adversely affected all sectors of the economy leading to budget cuts on social spending, including health and education (Agyepong $\&$ Adjei, 2008)). Limited resources engulfed the health sector and led to widespread shortages of essential medicines, supplies and equipment which adversely affected the quality of care in public health facilities (Dalinjong \& Laar, 2012).

This necessitated the introduction of the cash and carry system which entailed patients paying for drugs and some medical consumables when they visited the hospital, while the state absorbed all other costs, including consultation, salaries and emoluments for Doctors, Nurses and other healthcare workers in state hospitals (Owusu-Sekyere \& Chiaraah, 2014). This, according to Nyonator and Kutzin, (1999) was essentially a revolving drug fund that was introduced nationwide in 1992. The fee per drug item charged to users was related to the procurement cost of the item, marked-up with fixed percentages by central and regional medical stores. The cash and carry system was necessitated by the deterioration of the Ghanaian economy in the 1980s (Agyepong \& Adjei (2008). The World Bank, as part of the Structural Adjustment Programme, compelled Ghana to place great reliance on the free market system for resource allocation (Herbst, 1990). This occasioned the removal of subsidies and other forms of social interventions in a bid to salvage the ailing economy (Mensah et al., 2010). The cash and carry system ensured that the aged above 70 years of age, children under five years and pregnant women accessed health services at public health care provider centres without out of pocket payment (Owusu-Sekyere \& Chiaraah, 2014). The Cash and Carry system of paying for health care at the point of service put an enormous financial pressure on 
the poor and served as a major barrier to health care access, which led to health care disparities, particularly in the late 1990s (Owusu-Sekyere \& Bagah, 2014).

In recognition of the challenges brought by the cash and carry system, most countries, especially Sub-Saharan Africa, including Ghana have developed and implemented several polices aimed at improving their citizens' health status. The National Health Insurance Scheme (NHIS) is a social intervention program intended to provide financial risk protection against out of pocket health care expenditure for Ghanaians. The scheme is a pro-poor programme that focused much attention on targeting the core poor for exemption. The NHIS is financed by a national health insurance levy of $2.5 \%$ on certain goods and services, $2.5 \%$ monthly payroll deduction being part of the contribution to the Social Security and National Insurance Trust (SSNIT) for formal sector workers, government budgetary allocation and donor funding. Contributions from members of the informal sector are also made to the NHIS (Dalinjong \& Laar, 2012). The minimum benefits package under the NHIS includes general out-patient and in-patient care, oral health, eye care, comprehensive delivery care, diagnostic tests, generic medicines and emergency care. In all, over $95 \%$ of the most common disease conditions reported in healthcare facilities in Ghana are covered under the scheme (Gobah \& Liang, 2011). It however excludes highly specialized care such as dialysis for chronic renal failure, organ transplants and services provided under government vertical programs (Antiretroviral for the treatment of HIV/AIDS, immunization and family planning), and drugs not listed in the NHIS drug list are not covered.

Previous studies on the sustainability of the NHIS have concentrated on the financial and operational aspects with little emphasis on the perception of health care providers and subscribers (Alhassan et al., 2015; Owusu-Sekyere \& Bagah, 2014; Fusheini et al., 2012). Owusu-Sekyere and Bagah (2014) argued that lack of funds contributes to persistent indebtedness to service providers by the National Health Insurance Authority (NHIA). The NHIA Annual Report (2010) identified low premium collection at the scheme level as a challenge to the sustainability of the NHIS. It is interesting to note that premium payments accounts for less than 5\% of the scheme's total inflows as a result of the non-enforcement of the gatekeeper system (NHIA, 2010). Moreover, the abuse (abuse here refers to non-pregnant women enrolled onto the NHIS when in reality they are not) of the free maternal care programme has been identified as a contributor to increased claims, which accounts for $76.20 \%$ of NHIA total expenditure (Gobah \& Liang, 2011; NHIA, 2010). On the one hand, Schieber et al. (2012) suggests that lack of modern health management information system results in poor claims management, poor quality assurance, and high administrative costs, whereas Dalinjong and Laar (2012) found beneficiaries frequent visitations to health facilities with minor ailments and free riders' tendencies where insurance beneficiaries attend to collect drugs for their uninsured relatives and friends threatens the sustainability of the scheme.

Understanding the perceptions of the subscribers is significant as the scheme was implemented as a consequence of dissatisfaction and other associated weaknesses with the cash and carry system. The sustainability of the scheme to some extent depends on its ability to meet the health needs of Ghanaians. The subjective evaluation of the subscribers plays a kingpin role to the participation in the NHIS. If alternatives such as private health schemes and out of pocket 
payment proves viable, retention of subscribers may be difficult. Health care providers' perceptions and behaviours are equally critical in the sustainability of the NHIS. The realisation of the objective of the NHIS in the health delivery system depends on their behaviour towards the insured; particularly private health care providers since they are profit motivated. Once subscribers do not have confidence in the quality of care they receive, their participation in the NHIS might be affected; the sustainability of NHIS is highly dependent on membership.

It is against this background that this paper examined how the behaviour of healthcare providers is being influenced by the NHIS. The issue of subscriber perception and experience about healthcare providers remains a sightless spot in existing literature. This paper specifically assessed the perceptions of health care providers and how their attitude towards subscribers could threaten the sustainability of NHIS. The paper also assessed the perception and experiences of subscribers regarding service provision by health care providers.

\section{Materials and Methods}

\subsection{Study Setting}

The study was conducted in the Jirapa and Lambussie Districts of the Upper West Region, Ghana. The Jirapa and Lambussie districts have a total population of 88,402 and 51,654 respectively (GSS, 2012). Most residents of the districts are Dagaabas with few other tribes forming the minority. The main economic activity in the district is agriculture with few people involved in petty trading/commerce. However, the farmers are predominantly peasants (small-scale) for domestic consumption. With regards to health, the district has 37 accredited health providers for all categories, types and ownership of health care. These providers accredited with the NHIS basically provide primary health care to subscribers. The district office of the NHIS has a total active membership of 101,910 representing $72.8 \%$ coverage of the total population in both districts (Jirapa-Lambussie District Health Insurance Scheme, 2014). The study population constituted accredited health care providers and subscribers aged 18 years and above in both districts.

\subsection{Research Design and Sampling}

The study employed a mixed method research strategy. A combination of quantitative and qualitative (QUAN+QUAL) research methods was adopted as it provides a better understanding of research problems and complex phenomena than either approach alone (Creswell \& Plano, 2007). Also, the paper adopted this approach as it helps in developing a more complete understanding of a problem (Plano, 2010). Hence, the approach was considered appropriate in assessing the perceptions and experiences of health care providers and subscribers about the sustenance of the NHIS. An explanatory sequential mixed methods study with two phases was undertaken by the researchers. This approach was appropriate as it aided to determine the best participants with which to follow up or to explain the mechanism behind the quantitative results (Plano, 2010). In the first phase, a quantitative method (QUAN) was employed to assess clients' perceptions about the ability of accredited health providers to provide medicines, levels of satisfaction with waiting time and overall satisfaction by 
subscribers of service provision. With the use of survey questionnaires developed by the researchers, data was collected from 389 subscribers of the NHIS. This quantitative data was then analysed using frequency tables and percentages.

In the second phase, the study used data derived from the quantitative methods to develop interview guides which constituted the qualitative data (QUAL). The interview guide offered the researchers the opportunity to explore the perceptions of health care providers and how NHIS has influenced their behaviour in more detail; which has an effect on the sustainability of the NHIS. This interview guide was used to elicit information from staff of the 37 accredited health care providers in the two districts. The composition of staff for each of the various levels of health care was as follows; hospitals (3), health centres/clinics (2), Community Based Health Planning and Services (CHPS) (1), pharmacy/chemical shops (1), diagnostic centres (1). The medical directors, administrators, records staff, in-charges of health centres/clinics, CHPS compounds, diagnostic centres, Pharmacy/chemical shops were interviewed.

A cross section of 389 subscribers was determined at confidence level of $95 \%$ as the sample size using a mathematical formula suggested by Cochran (1977). The sample size was calculated as,

$\mathrm{n}=\mathrm{Z} 2(\mathrm{P})(\mathrm{q}) / \mathrm{d} 2$.

$\mathrm{n}=$ the desired sample size

$\mathrm{z}=$ the standard normal deviation 1.96

$\mathrm{p}=$ the proportion in the target population who access

health care with their NHIS card 50\% (0.50)

$\mathrm{q}=1.0-\mathrm{p}$

$\mathrm{d}=$ degree of accuracy desired at 0.05

$\mathrm{n}=(1.96) 2(0.5)(0.5)(0.05) 2$

$\mathrm{n}=384$

The authors made provision for a non-response rate of $5 \%(384+19=403)$. The authors discarded 14 responses which were incomplete and inconsistent and hence, placing the total sample size for the study at 389. These clients were interviewed using a structured questionnaire. The study had $100 \%$ response rate. Patient exit interviews were used in the quantitative methods to elicit information on clients' perceptions and experiences regarding the services they received from health care providers. Information on clients' level of satisfaction of health service provision was also collated. How clients perceived these services to affect the sustainability of NHIS was also elicited.

Simple random sampling was employed to recruit subscribers at the accredited health care providers for the study.

\subsection{Data Collection Instruments}

Structured questionnaire developed by the researchers were used to elicit the required data from subscribers selected for the study. The questionnaire was developed in English and translated to the local language, that is, Dagaare, to make the communication between the 
data collectors and respondents easy. Pretesting of the questionnaire was done in Karni community in the Jirapa district. Based on the feedback obtained from the pretesting, further refinement of the questionnaire was made. Six research assistants who were fluent in Dagaare were recruited, trained, and assigned as data collectors. The authors played a supervisory role. In collecting the data, a face-to-face interview technique was used.

Twenty (20) in-depth interviews (IDIs) were conducted with health care providers in the two study districts; 10 IDIs for each district. This was done to obtain information on the providers' perspective regarding the reimbursement process and the response of the providers to this process. Semi-structured interview guide was used for conducting the interviews, which was in English because all the participants could speak English fluently. Piloting of the interview guide was done with health care providers in the Jirapa District Hospital. The interviews were recorded with a digital voice recorder. The recordings were listened to and transcribed for the data analysis. Field notes were also taken alongside as a complement. The researchers conducted all the IDIs.

\subsection{Data Analysis}

The researchers developed a structured questionnaire for the collection of the required data from subscribers. The questionnaires were then administered to subscribers using face-to-face interview technique. The administered questionnaires were carefully edited, coded, processed and analysed with the Statistical Package for the Social Sciences Software, Version 16.0 and Microsoft excel. The quantitative data was first analysed using frequency tables, percentages generated from the SPSS database. The in-depth interviews were recorded and transcribed. This data was analysed manually using themes (Braun and Clarke, 2006). The researchers read through all the transcripts thoroughly and coded them. The codes were matched and generated into common themes and sub-themes for the paper. The integration of the two forms of data was done using the connecting and merging data approaches suggested by (Creswell and Plano, 2011). Merging data approach was done by combining the qualitative data in the form of texts with the quantitative data in the form of numeric information. Connecting the analysis of results from the initial phase (QUAN) with the data collection from the second phase (QUAL) of research also offered an opportunity for the integration of the two datasets.

\section{Results and Discussion}

The efficient and effective operation of the NHIS is dependent on key actors such as the scheme, the healthcare providers and the subscribers or clients. These three pillars are core to the functioning of the health insurance system. Any break or alteration in these three will affect the scheme. This paper discussed the perceptions and experiences of health care providers and how these affects the sustainability of the NHIS in the Jirapa and Lambussie Districts of the Upper West Region of Ghana.

\subsection{Perceptions of Health Care Providers on the Sustainability of the NHIS}

The success of the NHIS does not depend solely on the NHIA but also on the health service providers contracted to the scheme. The views of the providers were categorised into; the 
influence of NHIS on the revenue generation of providers, the influence of NHIS on accessibility of health services and the challenges that providers faced as a result of the implementation of NHIS.

\subsubsection{Boosting the Revenue Base of Health Providers}

Generally, providers admitted that NHIS had impacted positively on their revenue generation capacity. They explained that since funds are paid in bulk by the NHIS, planning for its use becomes easy. Revenue generated helped providers in their infrastructural development and the purchase of medicines and other consumables. An informant at Kanyiri Maternity Home, a private provider had this to say:

"The NHIS has boosted our revenue generation capacity, a private health provider conceded" (Informant, Kanyiri Maternity Home)

Providers explained that, they used to receive revenue in piecemeal during the cash and carry system and therefore could not carry out minor infrastructural projects.

"Any time NHIS pays us, we get the money in bulk. This is good as we can comfortably carry out developmental projects" (Informant, St Joseph's Hospital).

\subsubsection{NHIS and Access to Health Services}

The paper addressed the issue of NHIS and accessibility to health services. The study revealed that NHIS had increased access to health services in the Jirapa and Lambussie Districts. This was confirmed by the fact that attendance had increased significantly at provider sites as clients were not required to make payment at the point of service delivery. An informant at Karni Health Centre reports that:

"NHIS has helped a lot, now clients just pick their cards any time they are not feeling well and move to the nearest health provider. After all, they will not be required to make payment during service delivery" (Informant, Karni Health Centre).

Subscribers visit the health provider any time they are taken ill. This according to a nurse is good since the client condition will not deteriorate before coming to the hospital unlike during the cash and carry system. She says:

"People no longer wait until their conditions deteriorate before reporting to a help provider. They report to any facility closer to them at the slightest feel of sickness" (Informant, Karni Health Centre).

This finding is in tandem with that of Gobah and Liang (2011) whose study identified that NHIS had positively affected health seeking behaviour and utilization of healthcare services and hence, has the potential of reducing out-of-pocket payments at the point of service use. The results are also consistent with previous literature on NHIS and its influence on utilisation of health services (Saksena et al., 2010; Nguyen et al., 2010; Mensah et al., 2010). This clearly demonstrates that the NHIS has in a way removed the barrier to health services. 
Other studies conversely, argued that even though the NHIS contributed to increased utilization of formal health care services, the scheme did not necessarily improve the quality of health care in NHIS-accredited health facilities (Ghana Health Service, 2011).

\subsubsection{Challenges Facing Accredited Health Providers}

The study revealed that health providers faced numerous challenges with the operation of the NHIS. The increase in utilisation rates and abuse by subscribers were found to have a telling effect on the workload of staff and health infrastructure. Workload at NHIS accredited health providers has increased due to the pressure posed by the overwhelming clients attending these facilities without a corresponding increase in staff strength and motivation. At the St Joseph's Hospital, an informant reported that:

"Staff members are usually overwhelmed by the increasing number of NHIS clients attending this facility. There is so much pressure on our facilities. The wards are often full to capacity." (Informant, St Joseph's Hospital).

Gobah and Liang (2011) confirmed this in a study which showed that there exist over-utilisation and health shopping among health facilities by the insured. A similar study by Darlinjong and Laar (2012) suggested that service providers claim the introduction of the NHIS has given some subscribers the leverage to frequent health facilities at the slightest ailment which increases the workload of the health workers. A report by NHIA (2012) uncovered that some subscribers were accused of not completing the treatment course given to them by one service provider before jumping to another service provider to begin another treatment course. These findings were corroborated by an informant at Ullo Health Centre:

"These days' people visit the hospital anyhow. They can go to several facilities with the same complaint without even completing their medicines from the previous facility. They don't even respect the gate keeper system which is not good" (Informant, Ullo Health Centre).

This certainly is an evidence of moral hazard and a negative effect on the quality of healthcare offered due to increased utilisation. These are serious threats to the sustainability of the NHIS as the volume of claims will accordingly go up as "clients' facility shop".

Claims management is key to the survival of insurance institutions. The ability of the NHIS to contain cost and pay claims promptly remains a huge challenge. The study revealed that health providers were not satisfied with the time frame for the payment of their claims. The delays in claims payment affects the running of health facilities as they are unable to settle arrears owed pharmaceutical and utility companies.

"My brother, things are not easy for us here. For the past three to four months, we have not been able to pay our suppliers, water and electricity bills. This situation has been created by the inability of NHIS to pay us. We may even be disconnected from the national grid very soon if things don't change for the better" (Informant, St Joseph's Hospital).

This situation is even worse in private health providers that pay their staff salaries and public 
facilities that have causal staff on their payroll. Staff of these providers have complained about the inability of their employers to pay their salaries because NHIS owed them.

"Hmmm, we don't receive our salaries regularly. Whenever you ask management, they will tell you that NHIS has not paid yet. So we also keep borrowing from our friends to sustain our families until we are paid" (Informant, Muslim Community Clinic).

Admittedly, some providers also delay in claims submission which results in delays in the processing of these claims. It is the opinion of the authors that the delay in claims payment could affect quality of service health providers offer. Whenever accredited health providers run out of medicines, they are compelled to issue out prescription to clients to purchase medicines from outside of the facility. Laboratory services are sometimes also outsourced in situations like this as stock of consumables have been exhausted. Private providers sometimes will introduce co-payment as a stop-gap measure or better still turn their attention to non-insured clients.

"We have no option. Sometimes we ask clients to pay something small for us to buy reagents in order to keep the laboratory running. This is better than allowing the lab to collapse" (Informant, Muslim Community Clinic).

This is consistent with the findings of Dalinjong and Laar (2012) who established that the delay in the re-imbursement of claims to services providers affect their operations with regards to the purchase of medicines and other consumables. The NHIA (2013) annual report also confirmed the payment of claims as a challenge to the sustainability of the scheme. In instances like this, mostly private providers are compelled to introduce co-payment which defeats the purpose of the NHIS.

\subsection{Clients Perception about Service Provider's Ability to Provide Prescribed Medicines}

The availability of medicines especially essential ones at the pharmacy/dispensary of health providers form an important element in customers' assessment of services they receive. The results as illustrated in Table 1 indicate that $39.1 \%$ of clients rated the ability of providers to serve them with medicines as good compared to $9.8 \%$ who scored providers very poor. About $9.3 \%$ rated service provider's performance as very good. Clients who rated providers' ability to serve medicines as poor constituted $29 \%$ while $12.6 \%$ scored providers poor. The inability of providers to dispensed all medicines prescribed implied that, clients were referred to accredited pharmacy/chemical shops to be served. Gobah and Liang (2011) attributed poor quality of health services offered to clients to the unavailability of medicines. Clients explained that one would have to travel to the accredited pharmacy shops in order to obtain those medicines that could not be provided within health facilities. This they said introduced another dimension of expenditure as one would need to transport him/herself to the pharmacy. Kuu-ire expressed his frustration whenever one is being referred to go for medicines from an accredited pharmacy:

"At worst you would have to trek if you cannot afford taxi fee to the pharmacy shop you have been referred to, as a client lamented" (Kuu-ire). 
The worst affected would be children and the aged. A subscriber who could not get all prescribed medicines had this to say:

"each time I go to the hospital they give me only paracetamol weather headache, stomach pains, tooth ache or cold and will ask you to go to a drug store and buy rest" (Gando).

This practice had been identified as a source of leakage on the NHIS funds as pharmacy/chemical shops sometimes billed for medicines that were not dispensed to clients. In some cases, clients were required to "top-up" before medicines were offered to them. Clients who had such experiences described the NHIS not to be effective and hence, not prepared to re-enroll onto the system when their cards expire. This practice has the potential of threatening the sustainability of the NHIS.

Table 1. Rating of providers' ability to provide prescribed medicines

\begin{tabular}{lcc}
\hline Rating & Frequency & Percent \\
\hline Very good & 36 & 9.3 \\
Good & 152 & 39.1 \\
Fair & 114 & 29.3 \\
Poor & 49 & 12.6 \\
Very poor & 38 & 9.8 \\
Total & 389 & 100 \\
\hline
\end{tabular}

\subsection{Clients Level of Satisfaction with Waiting Time at Provider Site}

Waiting time at the provider end is a key determinant of quality of health care offered to clients. This paper sought to find out client's level of satisfaction with the time taken to be attended to by providers. The time spent before, during and after care is very crucial to the health of patients. In the context of this paper, the time spent before care is at the outpatient department, time spent during care is in the consultation room or during consultation/referral for laboratory investigation and the time spent after care is at the pharmacy. From Table 2, $36 \%$ of clients were somehow satisfied with the waiting time at health care provider site, as against $25.2 \%$ who indicated that they were satisfied. About $22.9 \%, 10.8 \%$ and $5.1 \%$ reported that they were dissatisfied, very dissatisfied and very satisfied respectively with the waiting time at the facilities that they visited. The poor quality of health services is due to the long waiting time at provider sites (Gobah \& Liang, 2011). This prolonged stay at facilities was equally attributed to the processes involved in using the NHIS card, thus validation and filling of forms. Respondents complained that this process takes a longer time to complete. It was alleged that more attention is been paid to the un-insured since they pay cash. The finding is in tandem with what Bruce et al. (2008), identified, that clients making out of pocket payment for health care services had shorter waiting times than their counterparts who were carrying health insurance cards. It is the opinion of the authors that this compromises quality of health services offered by providers and could discourage subscribers from visiting 
such facilities.

Table 2. Clients level of satisfaction with waiting time

\begin{tabular}{lcc}
\hline Rating & Frequency & Percent \\
\hline Very Satisfied & 20 & 5.1 \\
Satisfied & 98 & 25.2 \\
Somehow satisfied & 140 & 36.0 \\
Dissatisfied & 89 & 22.9 \\
Very dissatisfied & 42 & 10.8 \\
Total & 389 & 100.0 \\
\hline
\end{tabular}

\subsection{Assessment of Subscribers' Overall Level of Satisfaction of Service Provision}

Subscribers assessed their overall satisfaction with service provided to them by accredited health care providers. Table 3 revealed that $31.1 \%$ of clients were somehow satisfied with the overall services provided by facilities they visited. Those who were very satisfied and very dissatisfied constituted $13.6 \%$ and $12.6 \%$ respectively. The study further showed that $20.8 \%$ were satisfied as compared to $21.9 \%$ who expressed their dissatisfaction about the services they received. The basis for the above ratings included; attitude of staff, waiting time, availability of medicines at the facilities, physical examination by clinicians. This finding is in line with those of (Dzakpasu et al., 2012; MoH, 2007; Fusheini et al., 2012) who identified that patient satisfaction with the quality of health care in NHIS-accredited health facilities remains low especially with regard to staff attitudes and long waiting times, differential treatment for NHIS-insured and non-NHIS insured clients, quality of drugs covered by the NHIS, and limited client/community engagement in NHIS activities. It is of the view of the authors that this practice could erode confidence in the operation of the scheme thereby affecting (re) enrolment and hence demand for health service. This opinion corroborates with a study by Boateng and Awunyor-Vitor (2013); Agyei-Baffour et al. (2013), which suggest that demand for healthcare is determined by the quality of service provided and that even poor households limit their demand for health care when the services are poor quality, but are less sensitive to changes in quality of service.

Table 3. Assessment of subscribers' overall level of satisfaction of service provision

\begin{tabular}{lcc}
\hline Rating & Frequency & Percent \\
\hline Very satisfied & 53 & 13.6 \\
Satisfied & 81 & 20.8 \\
Somehow satisfied & 121 & 31.1 \\
Dissatisfied & 85 & 21.9 \\
Very dissatisfied & 49 & 12.6 \\
Total & 389 & 100 \\
\hline
\end{tabular}

\section{Implications for Stakeholders and Policy Makers}


The sustainability of the NHIS is a shared responsibility as observed by this study. The paper therefore highlighted the implications of the above findings and made recommendations thereafter for all stakeholders particularly policy makers.

The study established that NHIS had influenced utilisation rates in the Jirapa and Lambussie districts. Access to health care services had been promoted by the advent of NHIS thereby driving towards the ultimate goal of achieving universal health coverage. This obviously implies that NHIS is becoming a potent means to achieving universal health care in Ghana. Conversely, increased utilisation does not necessarily guarantee quality of health care. The paper therefore recommends that collaboration among stakeholders such as National Health Insurance Authority, Ministry of Health, Ghana Health Services, clients and accredited health providers should be strengthened. This would ensure that the NHIS is sustained and the ultimate goal of achieving universal health coverage is realized. Public health education should be vigorously pursued by all skaeholders. This would ensure that clients pay attention to health and safety issues. Once people take precautionary measures, the chances of falling sick and visiting the health provider becomes low.

The paper also identified perceived poor quality of services provided by accredited health care providers. Clients were generally not satisfied with the waiting time, attitude of staff among others. The findings regarding perceived poor quality of service suggests there is room for improvement in the health service delivery system, particularly from the client's perspective. The perception of the quality of health care could affect the patronage of such services both negatively and positively. Perceived poor quality health care could have a telling effect on (re) enrolment onto the NHIS. Subscribers may even 'hide' their NHIS cards to access health care as non-insured clients should such perception exist. The paper accordingly recommends that the Hospital Administration Management System should be adopted by providers to minimise the manual processing of clients' data that prolongs unnecessarily.

Furthermore, health care providers mentioned delays in claims re-imbursement as a challenge affecting their operation. This phenomenon could affect the effective operations of service providers thereby compromising service quality. To expedite claims processing for payment, this paper recommends that, the electronic processing of claims should be scaled up to cover all Teaching, Regional and District Hospitals. All private health facilities should be roped onto this electronic platform of claims processing. The paper further recommends that on the interim, the Ministry of Finance should expedite the release of funds to the NHIA for onward payment to providers. In the long term, a legislative act should be passed decoupling the NHIS fund from the consolidated fund account. This would ensure that revenue generated in the name of NHIS is lodged directly in to the account.

A general assessment of level of satisfaction by subscribers revealed a majority expressing their dissatisfaction. Subscribers purchase health services with pre-purchase expectations about anticipated performance. When outcome matches expectations, confirmation occurs. Disconfirmation occurs when there are differences between expectations and outcomes. Negative disconfirmation occurs when product/service performance is less than expected. 
Positive disconfirmation occurs when product/service performance is better than consumer expectations, and dissatisfaction is caused by negative disconfirmation of subscribers' expectations. Once a subscriber is dissatisfied, the tendency to (re) enroll onto the NHIS is low. This obviously is a sustainability threat.

Abuse by subscribers was also identified as a potential threat to the sustainability of NHIS. The study showed that subscribers do facility shopping thereby leading to waste in the system. Sensitisation by health care providers and NHIS staff on the dangers of multiple visits would ultimately help in resolving the situation. Health promotion should also be a key activity by providers. The introduction of capitation as another form of claims payment to providers should equally be scaled up to the entire country. This would ensure that subscribers are 'tied' to specific facilities for primary health care.

\section{Conclusion}

This paper has added to the ongoing debate regarding the sustenance of the NHIS in Ghana. It specifically assessed the perceptions and experiences of health care providers and subscribers and how these could threaten the survival of the NHIS. The study has established that NHIS was promoting access to health services in the two studied districts, which ultimately is geared towards achieving universal health coverage. The inability of health care providers to provide all essential medicines was also identified as a challenge to subscribers. Perceived poor quality of health care as expressed in subscribers' low satisfaction of care is also an issue that needs attention by stakeholders. The scheme has the potential of removing the financial barrier that existed with the cash and system as revealed through this study. However, the apparent sustainability threats as identified by this paper would have to be contended by all stakeholders (Ministry of health, Ghana Health Service, NHIA, clients, providers, government among others) for the scheme to live up to its mandate.

\section{References}

Addae-Korankye, A. (2013). Challenges of Financing Health Care In Ghana: The case of National Health Insurance Scheme (NHIS). International Journal of Asian Social Science, $3(2), 511-522$

Agyei-Baffour, P., Oppong R. and Boateng D. (2013). Knowledge, perceptions and expectations of capitation payment system in a health insurance setting: A repeated survey of clients and health providers in Kumasi, Ghana. BMC Public Health, 13: 1220-1220. HTTP://DX.DOI.ORG/10.1186/1471-2458-13-1220

Alhassan, R. K., Duku, S. O., Jassens, W., Nketiah-Amponsah, E., Spieker, N., \& van Ostenberg, P. (2015). Comparison of perceived and technical health care quality in primary health facilities: implications for a sustainable national health insurance scheme in Ghana. PLoS ONE, 10(10), 1-19.

Agyepong, I. A., \& Adjei, S. (2008). Public social policy development and implementation: a case study of the Ghana National Health Insurance scheme. Health Policy and Planning, 23(2), 150-160. http://dx.doi.org/10.1093/heapol/czn002 PMID: 18245803 
Arhinful, D. (2003). The solidarity of self-interest: social and cultural feasibility of rural health insurance in Ghana. In Research report 71. African Studies Centre, Leiden, Netherlands.

Boateng, D., \& Awunyor-Vitor, D. (2013). Health insurance in Ghana: Evaluation of policy holders' perceptions and factors influencing policy renewal in the Volta region. Int. J. Equity Health, 12, 1-10. http://dx.doi.org/10.1186/1475-9276-12-50

Braun, V., \& Clarke, V. (2006). Using thematic analysis in psychology. Qualitative Research in Psychology, 3(2), 77-101.

Bruce, E., Narh-Bana, S., \& Agyepong, I. (2008). Community satisfaction, equity in coverage and implications for sustainability of the Dangme west health insurance scheme. Accra Ghanaian Dutch Collaboration for Health Research and Development. In Technical Report Series No 9.

Creswell, J., \& Plano Clark, V. (2007). Designing and Conducting Mixed Methods Research, Sage, Thousand Oaks.

Dalinjong \& Laar (2012). The national health insurance scheme: perceptions and experiences of health care providers and clients in two districts of Ghana. Health Economics Review, 13(1), 27-35.

Dzakpasu, S., Soremekun, S., Manu, A., ten Asbroek, G., Tawiah, C., \& Hurt, L. (2012). Impact of Free Delivery Care on Health Facility Delivery and Insurance Coverage in Ghana's Brong-Ahafo Region. PLoS ONE, 7(11), 1-9

Fusheini, D., Marnoch, G., \& Grey, A. M. (2012). The Implementation of the National Health Insurance Programme in Ghana, an Institutional Approach. Paper presented at the 62nd Political Studies Association. Annual International Conference in Defence of Politics.

Frimpong, P. B. (2013). The quest of equity in the provision of health care in Ghana. African Review of Economics and Finance, 4(2), 1-19.

Ghana Health Service (GHS). (2011). Annual Report, Ministry of Health and Ghana Health Services, Accra, Ghana.

Gobah, F. F. K., \& Liang, Z. (2011). The National Health Insurance Scheme in Ghana: Prospects and Challenges: a Cross-Sectional Evidence. Global Journal of Health Science, 3(2), 90-101.

Cochran, G. M. (1977). Sampling Techniques (3rd ed.). New York, NY: John Wiley \& Sons.

Jirapa-Lambussie District Health Insurance Scheme. (2014). Annual Report.

Kyomugisha EL, Buregy eya E, Ekirapa E, Mugisha JE, and Bazeyo W. (2009). Strategies for Sustainability and equity of pre-payment health schemes in Uganda. African Health Sciences, 9(s2), s59-s65

McIntyre D. (2007). Learning from experience: health care financing in low- and middle 
income countries, Global Forum for Health Research: Geneva

Mensah, J., Oppong, J. R., \& Schmidt, C. M. (2010). Ghana's National Health Insurance Scheme in the Context of the Health MDGs: An Empirical Evaluation Using Propensity Score Matching. Health Economics, 19, 95-106.

Ministry of Health (2007). Independent review of 2006 programme of work (POW) First Draft. Ministry of Health, Accra, Ghana.

National Health Insurance Authority (2010). Annual Report, 2010. NHIA. Accra

Nguyen et al. (2011). The financial protection effect of Ghana National Health Insurance Scheme: evidence from a study in two rural districts. International Journal for Equity in Health, 10, 4. http://dx.doi.org/10.1186/1475-9276-10-4

Nyonator, Kutzin \& Joseph (1999). Health for some? The effects of user fees in the Volta Region of Ghana. Health for all, 14(4), 21-31.

Owusu-Sekyere E. and Bagah D. A (2014). Towards a Sustainable Health Care Financing in Ghana: Is the National Health Insurance the Solution?

Owusu-Sekyere, E, \& Chiaraah, A. (2014). "Demand for Health Insurance in Ghana: What Factors Influence Enrolment?” American Journal of Public Health Research, 2

Plano Clark, V. L. (2010). The adoption and practice of mixed methods: U.S. trends in federally funded health-related research. Qualitative Inquiry, 6(6), 428-440.

Saksena, P., Antunes, A. F., Xu, K., Musango, L., \& Carrin, G. (2010). Impact of mutual health insurance on access to health care and financial risk protection in Rwanda. Discussion paper, 3/2010.WHO.Geneva.

Scheiber, George, Cheryl Cashin, Karima Saleh, and Rouselle L. (2012). Health financing in Ghana. Washington, DC: World Bank. http://dx.doi.org/10.1596/978-0-8213-9566-0

\section{Copyright Disclaimer}

Copyright for this article is retained by the author(s), with first publication rights granted to the journal.

This is an open-access article distributed under the terms and conditions of the Creative Commons Attribution license (http://creativecommons.org/licenses/by/3.0/). 